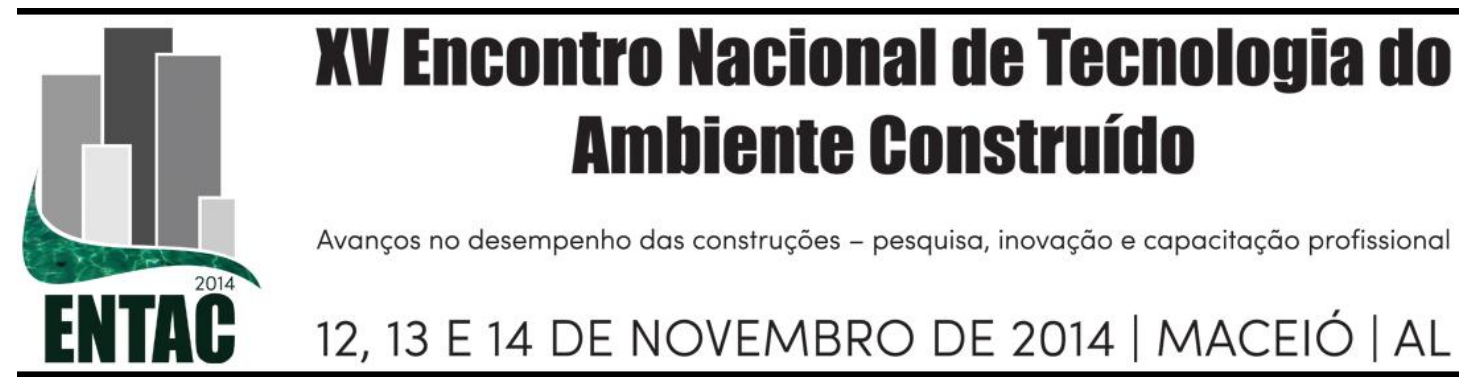

\title{
EFICIÊNCIA ENERGÉTICA EM EDIFICAÇÕES NA ATUAÇÃO DOS ARQUITETOS E URBANISTAS DE MATO GROSSO DO SUL
}

\author{
BUGES, Nathalya Luciano (1); ANDREASI, Wagner Augusto (2); QUEIROZ, \\ Adriane Angélica Farias Santos Lopes de (3) \\ (1) UFMS, (67) 8124-9361, e-mail: nathybuges@ gmail.com (2) UFMS, e-mail: \\ wagner.andreasi@ufms.br (3) UFMS, e-mail: adriane.queiroz@ufms.com.br
}

\begin{abstract}
RESUMO
A etiqueta de edificações do Programa Brasileiro de Etiquetagem — Etiqueta PBE Edifica — é um importante instrumento para a Política Nacional de Conservação de Energia, possuindo, portanto, perspectiva de compulsoriedade. Logo, importa que os profissionais estejam preparados para a obrigatoriedade dela e para as mudanças que ocorrerão no mercado da construção em decorrência desta nova regulamentação. Objetivando identificar as possíveis dificuldades para a implantação da Etiqueta PBE Edifica em Mato Grosso do Sul, está em desenvolvimento um trabalho de mestrado para analisar o perfil dos profissionais com formação em áreas relacionadas à construção civil, atuantes nesse estado. A pesquisa coletou diversas informações partindo do objetivo exposto. Este artigo, entretanto, será limitado aos dados fornecidos pelos arquitetos e urbanistas sobre opinião e comportamento relacionados à Eficiência Energética em Edificações (EEE). O levantamento foi realizado através de um questionário enviado para todos os profissionais cadastrados no Conselho de Arquitetura e Urbanismo de Mato Grosso do Sul - CAU/MS. O questionário utilizado foi baseado nos regulamentos que controlam o processo de etiquetagem, seguindo também recomendações científicas consolidadas que definem métodos para construção de questionários. O baixo índice de retorno das respostas, aproximadamente $6 \%$, indica que a maioria dos arquitetos não apresenta interesse pelo tema. Os resultados demonstraram que $41 \%$ desses profissionais acreditam possuir conhecimento mediano sobre EEE e 46,3\% julgam aplicar regularmente práticas condizentes com o tema em sua atuação profissional. Porém, quando comparado às respostas fornecidas sobre atitudes profissionais específicas, necessárias para o desempenho energético adequado de uma edificação segundo a Etiqueta PBE Edifica, 73,5\% dos arquitetos demonstraram nunca, ou raramente utilizar as estratégias para redução do consumo de energia elétrica. Mostra-se necessário conscientizar os arquitetos sobre a importância da EEE e da etiquetagem, e principalmente esclarecer que a atuação seguindo esses parâmetros é mais exigente que o pensamento profissional comum sobre esses temas.
\end{abstract}

Palavras-chave: Eficiência Energética em Edificações, Etiqueta PBE Edifica, Arquitetos e Urbanistas, Questionário

\begin{abstract}
The label for buildings by the Brazilian Labeling Program - Etiqueta PBE Edifica - is an important tool for the National Energy Conservation Policy, therefore, having compulsory perspective. Thus, it is important that professionals are prepared for its mandatory and for the changes that will occur in the construction industry as a result of this new regulation. In order to identify possible difficulties during the implementation of Etiqueta PBE Edifica in Mato Grosso do Sul, a master's thesis is in development to analyze the profile of professionals with training in fields related to civil construction working in this state. The research collected varied information from the exposed objective. This paper, however, will be limited to the data provided by architects and urbanists about their opinion and behavior toward Energy Efficiency in Buildings (EEE). The survey was conducted through a questionnaire, which was sent to all professionals registered at Architecture and Urbanism Council of Mato Grosso do Sul - CAU/MS. The questionnaire adopted was based on the regulations that rule the labeling procedure, also following
\end{abstract}


consolidated scientific recommendations that define questionnaire development methodologies. The low return rate of responses, approximately 6\%, indicates that most architects have no interest in the subject. The results showed that $41 \%$ of these professionals believed to have average knowledge about EEE and $46,3 \%$ judged to apply consistent practices of the subject in their professional routine. However, when compared to the responses provided on specific professional attitudes, necessary for proper energy performance of a building according to Etiqueta PBE Edifica, 73,5\% of the architects showed to never, or rarely, use strategies to reduce consumption of electricity. It is essential to educate architects about the importance of EEE and labeling, and mainly clarify that the practices following these parameters are more demanding than the conventional professional concept on these topics.

Keywords: Building Energy Efficiency, Etiqueta PBE Edifica, Architects and Urban Planners, Questionnaire

\section{INTRODUÇÃO}

Em virtude da crise energética ocorrida em 2001, o governo sancionou a Lei 10.295/2001 onde estabeleceu a necessidade de criar requisitos para garantir níveis mínimos de Eficiência Energética, ou máximos de consumo, para diversos produtos, dentre eles as edificações. O desenvolvimento desses níveis resultou na criação da Etiqueta de Edificações do Programa Brasileiro de Etiquetagem - Etiqueta PBE Edifica que, mesmo estando em regime voluntário, possui perspectiva de obrigatoriedade devida sua importância para a Política Nacional de Conservação de Energia (MME, 2011).

Para tanto, desde as primeiras publicações relacionadas à etiqueta, a necessidade de divulgação era ressaltada, visto ser importante preparar os profissionais envolvidos na construção civil para as mudanças que ocorrerão quando ela se tornar compulsória, garantindo a adesão e contribuindo para o sucesso da certificação (MME, 2009). Contudo, em Mato Grosso do Sul, os profissionais demonstraram baixo interesse em participar de eventos e palestras criadas para difundir os conceitos de Eficiência Energética em Edificações (EEE) e para auxiliar no entendimento da Etiqueta PBE Edifica, atitude que sugere possíveis problemas para a implantação do processo de etiquetagem no estado. Das 2061 etiquetas PBE Edifica expedidas 1746 foram para São Paulo, 96 para o Ceará, 88 para Minas Gerais e 73 para Santa Catarina, enquanto nenhuma foi expedida para Mato Grosso do Sul (INMETRO, 2014).

Com a finalidade de entender os motivos desse comportamento e traçar estratégias para facilitar a adequação do mercado da construção civil sul-mato-grossense, está em desenvolvimento um trabalho de mestrado buscando traçar o perfil de sete categorias de profissionais envolvidos com a concepção e execução de edificações. Esta pesquisa, de caráter exploratório, levantou informações sobre prática profissional, formação, comportamentos e opiniões a respeito da EEE e do Programa Brasileiro de Etiquetagem por meio de um questionário digital criado na ferramenta Formsite. Este artigo, entretanto, se restringirá aos dados de opinião e comportamento relacionados à EEE fornecidos pelos arquitetos e urbanistas residentes no estado.

\section{REVISÃO BIBLIOGRÁFICA}

A Etiqueta PBE Edifica classifica o edifício de acordo com cinco níveis de eficiência, sendo "A" para o melhor desempenho e "E" para o pior, auxiliando, desta forma, o consumidor em sua decisão de compra. Ela é concedida por meio de dois mecanismos de avaliação da conformidade: a etiquetagem e a inspeção.

Durante a fase de projeto, a edificação deve ser submetida a uma análise por meio dos requisitos contidos no Regulamento Técnico da Qualidade do Nível de Eficiência Energética (RTQ), que indicará sua eficiência energética e possibilitará a emissão da 
Etiqueta de Projeto. Após a construção do edifício, este será inspecionado segundo os critérios expostos no Regulamento de Avaliação da Conformidade do Nível de Eficiência Energética (RAC), a fim de verificar não conformidades na execução e possíveis influências no nível de eficiência energética obtido na fase de projeto. Para edificações construídas, o processo de obtenção da Etiqueta PBE Edifica é o mesmo, existindo também uma etiqueta para a análise do projeto e outra para a edificação construída (MME, 2009).

Além de regular a inspeção, o RAC descreve outros procedimentos necessários para obtenção da etiqueta, dispondo sobre os direitos e deveres dos envolvidos no processo de etiquetagem, os documentos que devem ser encaminhados em todas as fases da avaliação, bem como modelos de formulários, disposições sobre os organismos de inspeção acreditados, dentre outras questões necessárias à correta obtenção e funcionamento da Etiqueta PBE Edifica (MME, 2009).

Por sua vez, o RTQ estabelece os critérios técnicos que devem ser avaliados para classificação do nível de eficiência de uma edificação. Devido à natureza diversa das edificações, foram desenvolvidas regulamentações distintas para edificações não residenciais (RTQ-C) e residenciais (RTQ-R).

O Regulamento Técnico da Qualidade do Nível de Eficiência Energética de Edifícios Comerciais, de Serviço e Públicos (RTQ-C) foi publicado em julho de 2009 (MME, 2011). Segundo ele, a classificação de eficiência pode ser realizada para a envoltória da edificação, seu sistema de iluminação e seu sistema de condicionamento de ar. Com base no desempenho energético de cada sistema, nas bonificações e nos pré-requisitos estabelecidos, tem-se a eficiência global da edificação (MME, 2009).

Em 2010 foi publicado o Regulamento Técnico da Qualidade do Nível de Eficiência Energética para Edificações Residenciais (RTQ-R) (MME, 2011). Ele estabelece os critérios para avaliação do desempenho energético de habitações unifamiliares, multifamiliares e de áreas de uso comum, gerando uma etiqueta diferente para cada um dos três casos. O nível final de eficiência para cada etiqueta é definido, assim como no RTQ-C, pelo desempenho de sistemas, presença de bonificações e análise de pré-requisitos.

Os procedimentos para determinação da eficiência energética da edificação são complexos, principalmente quando definidos pelo método de simulação, pois utiliza de programas computacionais que exigem conhecimento aprofundado tanto dos conceitos de desempenho térmico quanto do intrincado funcionamento do próprio software.

Devido a trechos de difícil compreensão, a regulamentação está em constante discussão pela Rede de Eficiência Energética em Edificações (R3E), resultando em correções e contínua melhoria do material em questão. Quanto à complexidade da certificação, juntamente com os regulamentos foram lançados manuais para facilitar a aplicação dos RTQs, bem como cursos, palestras e outros materiais a fim de disseminar os princípios de aplicação da etiquetagem de EEE.

A utilização dos regulamentos técnicos também foi motivo de diversos estudos, como o de Silva, Giongo e Andreasi (2011) que desenvolveram planilhas eletrônicas para facilitar os procedimentos de cálculo dispostos no RTQ-C, Fossati e Lamberts (2010) que discutiram sobre a avaliação da envoltória pelo método prescritivo no RTQ-C a partir do estudo de dez escritórios em Florianópolis, e Pereira et al (2010), que também contribuiram para o entendimento e disseminação da aplicação dos regulamentos e seus conceitos por meio de um curso à distância sobre simulação de EEE.

Fossati e Lamberts (2010) afirmam que poucos são os profissionais que se preocupam com a bioclimatologia aplicada ao projeto das edificações, surgindo desta forma os 
regulamentos de eficiência energética para "estimular o emprego de técnicas de projeto e estratégias bioclimáticas para a criação de soluções arquitetônicas mais adequadas ao ambiente climático em que estão inseridas".

Mesmo apresentando algumas limitações, a certificação de eficiência energética é uma ferramenta importante, pois, além de apresentar grande potencial para reduzir a demanda nacional de energia, é útil para esclarecer ao consumidor, de maneira didática, sobre a edificação de interesse, demonstrando a possibilidade de redução de gastos e valorização do imóvel através de sua qualidade energética e de conforto ambiental (KRÜGER e MORI, 2012; FOSSATI e LAMBERTS, 2010).

\section{METODOLOGIA}

Devido ao caráter exploratório da pesquisa, o instrumento de coleta de dados utilizou uma abordagem qualitativa. Para desenvolvimento do questionário foram seguidas as recomendações de Gil (2011), Marconi e Lakatos (2011), Richardson (2009) e Günther (2003) quanto à organização da ferramenta, à redação e à ordem das questões e alternativas, aos elementos complementares e às formas de envio, dentre outras considerações. A ferramenta de coleta de dados foi estruturada em quatro sessões entituladas como "Formação", "Campo de Atuação Profissional", "Dados Gerais" e "Eficiência Energética em Edificações", porém este artigo se restringirá a analisar somente os resultados desta última.

Para a concepção das questões da seção "Eficiência Energética em Edificações" foi realizado um estudo exaustivo dos regulamentos referentes à Etiqueta PBE Edifica RTQ-C, RTQ-R e RAC - nas versões mais atuais no momento do desenvolvimento do instrumento de pesquisa. De acordo com cada um deles, foram extraídos os temas principais (construtos), compostos por itens específicos (variáveis), a partir dos quais foram concebidas as questões sobre atividade profissional presentes no Anexo A.

As questões contidas no Anexo A estão na versão utilizada para o pré-teste, não representando a primeira redação delas. Inicialmente todas as variáveis possuíam uma indagação contando, portanto, com 28 perguntas. Entretanto, foi necessário reduzir este número para não tornar o preenchimento exaustivo, visto que seriam acrescidas outras questões de caráter perceptivo e de conhecimento sobre o Programa Brasileiro de Etiquetagem. Para esta redução, variáveis similares foram unidas e perguntas menos importantes no contexto dos regulamentos de EEE foram excluídas, buscando criar um conjunto capaz de diagnosticar as atitudes tomadas na prática profissional de acordo com os princípios da eficiência energética e do conforto ambiental.

As questões de caráter perceptivo sobre o PBE foram criadas para entender o que os participantes da pesquisa pensam a respeito de seus conhecimentos, suas práticas profissionais, sua formação relacionada com a temática do trabalho e sobre a Etiqueta PBE Edifica. Elas se mostraram necessárias a fim de estabelecer um paralelo entre o que os respondentes entendem por EEE e o que de fato aplicam.

As indagações foram ordenadas das mais gerais para as mais específicas, seguindo uma progressão que permitisse o desencadeamento lógico das questões e evitasse o efeito de contágio, buscando não permitir a influência de perguntas anteriores nas respostas fornecidas. Como opção de resposta a maioria das perguntas apresenta uma escala de cinco pontos, sendo acrescida em casos necessários a opção "não se aplica" ou similar.

Como diversos profissionais, mesmo possuindo a atribuição, comumente não atuam em todos os seguimentos da sua profissão, verificou-se ser mais apropriado filtrar as 
perguntas específicas, vinculando-as não a formação, mas sim ao tipo de atividade que o respondente afirma desempenhar. Desta forma, cada participante respondeu somente as questões relacionadas às suas atividades profissionais.

O questionário foi construído em ambiente digital através da ferramenta Formsite, com a finalidade de torná-lo mais prático, claro e atrativo, contando também com a facilidade na tabulação dos dados e a redução dos custos se comparado ao envio por correio. Para tanto, os conselhos de classe que representam os profissionais pesquisados colaboraram com o estudo possibilitando o envio dos questionários por meio de informativos enviados por e-mail.

Depois de finalizados, questionário e carta de apresentação da pesquisa foram submetidos ao processo de pré-teste para aprimoramento da ferramenta e do método de coleta de dados. Ele foi realizado em três fases, contando primeiramente com a participação de quatro colaboradores vinculados ao Laboratório de Análise e Desenvolvimento de Edificações (LADE) para verificar o questionário quanto aos conceitos de EEE e a Etiqueta PBE Edifica. Na segunda fase o instrumento foi revisado quanto sua estrutura e redação das questões por profissional com experiência em pesquisas sociais e desenvolvimento de questionários. Por fim, foi realizado o envio da pesquisa para 100 profissionais da construção civil no estado de Mato Grosso do Sul.

Para a terceira fase do pré-teste a amostra foi dividida proporcionalmente à quantidade de profissionais por formação e por microrregião do estado para que, além de verificar a ferramenta e o método de coleta, fosse possível testar o planejamento amostral definido. Devido ao baixo índice de retorno, que correspondeu a aproximadamente $7 \%$ dos questionários enviados, o planejamento amostral foi abandonado e, como nova postura, adotou-se enviar o questionário para todos os profissionais estudados cadastrados no Conselho Regional de Engenharia e Agronomia - CREA/MS e no Conselho de Arquitetura e Urbanismo de Mato Grosso do Sul (CAU/MS), utilizando as respostas que retornassem, pautado no disposto por Bell (2008) sobre a possibilidade de trabalhar com amostra de oportunidade quando uma amostra aleatória for inviável.

A fim de aumentar o número de respostas, antes de enviar a pesquisa, foi realizado um contato prévio informando sobre o estudo e solicitando apoio. Também foram enviados lembretes durante o período em que o questionário se manteve aberto. Desta forma, o envio final da ferramenta contou com cinco fases: contato prévio, envio da carta de apresentação, primeiro lembrete, segundo lembrete e, por fim, aviso de encerramento da pesquisa, todos com o link do questionário, com exceção do contato prévio.

Os dados sobre a seção "Eficiência Energética em Edificações", obtidos através das respostas fornecidas pelos arquitetos e urbanistas do estado, foram analisados considerando somente os questionários devolvidos completos. As respostas foram descritas por meio de porcentagem para facilitar a visualização e comparação.

Importa ainda ressaltar que não foi possível obter dados de uma amostra probabilística devido aos problemas de coleta anteriormente citados, portanto os resultados encontrados neste trabalho não podem ser generalizados para a população estudada, não sendo possível utilizar as ferramentas estatísticas para estimar a representatividade da amostra. Entretanto, os dados obtidos ainda contribuem com informações importantes e, a partir de um caráter exploratório, podem ser considerados indicadores do comportamento da população alvo, auxiliando no entendimento da prática profissional com eficiência energética na construção civil, visto não existir nenhuma informação similar com enfoque no estado de Mato Grosso do Sul. 


\section{RESULTADOS E DISCUSSÕES}

Os questionários foram enviados para, aproximadamente, 7.500 profissionais relacionados com a construção civil sendo que, em torno de 1.500 são arquitetos e urbanistas. Após quatro meses de pesquisa e o envio de três lembretes, 307 questionários foram respondidos, porém somente 196 foram totalmente preenchidos. Os arquitetos e urbanistas foram responsáveis pelo retorno de 83 questionários completos $(42,3 \%)$, número muito expressivo se comparado à porcentagem que estes profissionais representam dentro da população estudada $(\cong 20 \%)$.

As cinco primeiras perguntas da seção "Eficiência Energética em Edificações" trataram da percepção dos profissionais sobre suas habilidades relacionadas ao tema, ou seja, coletaram informações sobre conhecimento e atuação através do ponto de vista e do autojulgamento do respondente. Primeiramente o participante foi questionado sobre os conhecimentos que supõe ter, quando foi perguntado "Conhece os conceitos de Eficiência Energética em Edificações?”. Dos arquitetos que responderam à pesquisa, $41 \%$ afirmaram conhecer regularmente os conceitos de EEE, 31,3\% disseram conhecer pouco, $21,7 \%$ conhecem bem, 3,6\% não conhecem e 2,4\% afirmaram conhecer muito bem o assunto (Gráfico 1).

\section{Gráfico 1 - Conhece os conceitos de EEE?}

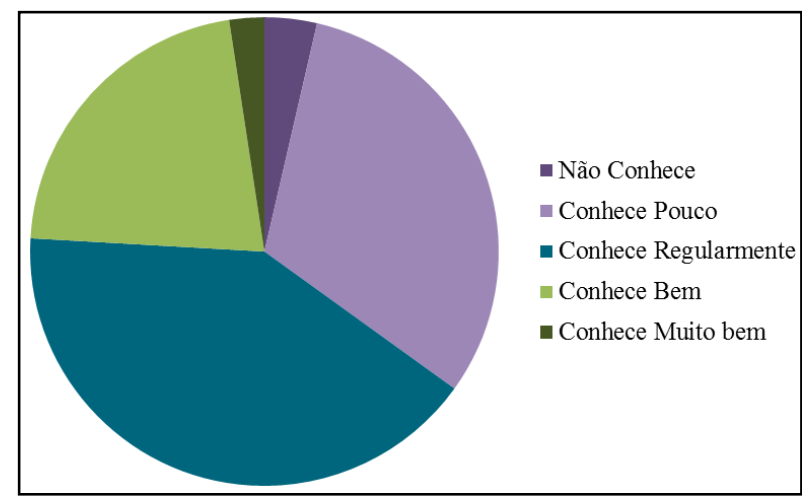

Fonte: Elaboração própria

\section{Gráfico 2 - Cursou disciplina na graduação com enfoque em EEE?}

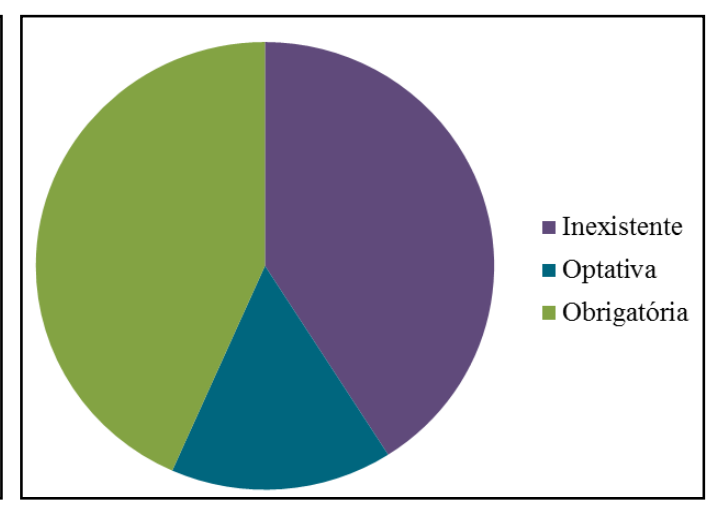

Fonte: Elaboração própria

Quando questionados sobre a existência de uma disciplina na graduação que possuísse enfoque em EEE, 43,4\% dos arquitetos responderam que cursaram uma disciplina obrigatória com enfoque em EEE, enquanto $41 \%$ não tiveram qualquer disciplina com esta característica e $15,7 \%$ realizaram disciplina optativa sobre o tema (Gráfico 2). Visto que somente $3,6 \%$ dos arquitetos afirmaram não conhecer os conceitos de EEE e que $41 \%$ não possuíram este conhecimento na graduação, pode-se entender que ele foi adquirido através de outros meios não identificados na fase de análise delimitada neste artigo.

Para a indagação "Em seu campo de atuação profissional, os conhecimentos sobre Eficiência Energética em Edificações são necessários?" somente um participante respondeu negativamente. Porém, quando analisado quais as atividades ele disse desenvolver, verificou-se que sua atuação profissional está focada em projeto arquitetônica, área fundamental para a aplicação da EEE.

Como a pergunta "Os conhecimentos sobre Eficiência Energética em Edificações fornecidos por seu curso de graduação são suficientes ou não, para aplicá-los à realidade 
de seu campo de atuação profissional?" depende de uma resposta positiva da questão anteriormente citada, a quantidade de arquitetos que contribuiu com esta questão foi 82 . $\mathrm{O}$ resultado apresentou que 58,5\% dos respondentes acreditam que os conhecimentos sobre EEE fornecidos na graduação são pouco suficientes para aplicação profissional; $32,9 \%$ defenderam que os conhecimentos são insuficientes e somente $8,5 \%$ afirmaram que a graduação forneceu conhecimento suficiente sobre EEE.

A última questão considerada como de percepção foi: "Em sua profissão, com que frequência você utiliza os conhecimentos sobre Eficiência Energética em Edificações?". Ela também possuiu 82 respostas, em razão dos mesmos motivos citados para a questão anterior. Segundo as respostas coletadas, $46,3 \%$ dos profissionais estudados neste artigo julgam utilizar regularmente os conhecimentos de EEE em sua atuação profissional. Os que afirmaram utilizar quase sempre representam 20,7\%, os que utilizam sempre $17,1 \%$, os que raramente utilizam $12,2 \%$, enquanto os que disseram nunca utilizar correspondem a 3,7\% dos questionários analisados.

Foram realizadas 19 questões sobre prática profissional e EEE de acordo com o RTQ-C, o RTQ-R e o RAC. O intuito foi verificar quanto os participantes da pesquisa já aplicam em suas rotinas profissionais os conceitos mais importantes para a Etiqueta PBE Edifica, possibilitando um diagnóstico preliminar a respeito da dificuldade de implantação desta em Mato Grosso do Sul. Também foi possível comparar a utilização percebida pelos profissionais, apresentada no parágrafo anterior, e a utilização real, definida de acordo com as 19 questões específicas sobre os regulamentos, presentes no Anexo A.

Para tanto, cada uma das respostas às 19 questões foi transformada em um número de 0 a 4, de acordo com a escala de cinco pontos. Então, calculou-se, para cada participante, a média aritmética dos números obtidos na conversão das respostas. Este valor médio foi considerado como o índice final do respondente, representando a utilização real dos conceitos de EEE na prática profissional dele. $O$ índice foi novamente transformado em uma alternativa correspondente na escala 'nunca', 'raramente', 'regularmente', 'quase sempre' e 'sempre', possibilitando a comparação com a questão "Em sua profissão, com que frequência você utiliza os conhecimentos sobre eficiência energética em edificações?" (Gráfico 3).

\section{Gráfico 3 - Utilização dos conceitos de EEE}

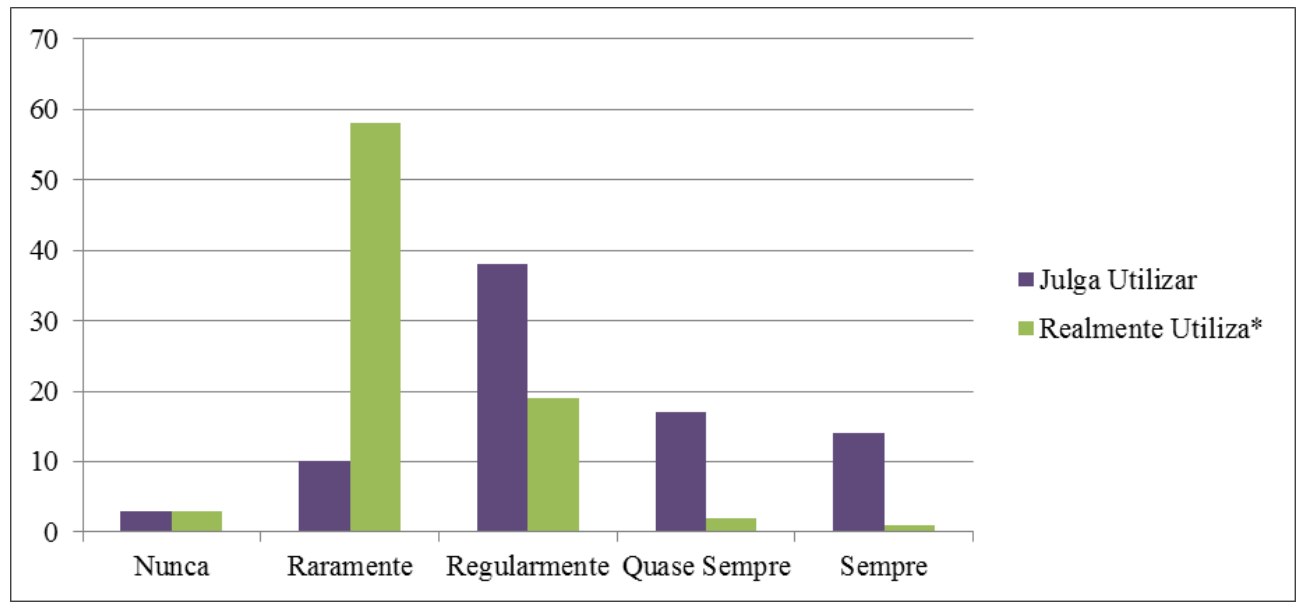

*De acordo com o RTQ-C, o RTQ-R e o RAC.

Fonte: Elaboração própria 
Contrário à percepção dos arquitetos e urbanistas sobre a utilização da EEE em suas práticas profissionais, as questões criadas a partir dos regulamentos mostraram que a maior parte dos respondentes raramente atua com eficiência energética. Se somados os percentuais dos que responderam 'raramente' com os que responderam 'regularmente' e 'nunca', verifica-se que 96,4\% dos participantes da pesquisa não utilizam a EEE em frequência satisfatória.

Para encerrar a seção do questionário sobre EEE, foram desenvolvidas duas perguntas sobre a Etiqueta Nacional de Conservação de Energia (ENCE) do INMETRO, e três sobre a Etiqueta PBE Edifica. Sobre a ENCE foi indagado primeiramente o quanto o respondente a conhecia, obtendo como resposta que 31,3\% conhecem pouco, 30,1\% não conhecem, $18,1 \%$ conhecem bem, $15,7 \%$ conhecem regularmente e 4,8\% conhecem muito bem (Gráfico 4). Todos os 58 arquitetos que indicaram algum nível de conhecimento sobre a ENCE também responderam a questão: "Em suas especificações de projeto, você escolheria algum sistema ou aparelho consumidor de energia elétrica (bombas centrífugas, motores, sistemas de iluminação, ar condicionado, dentre outros) que não possuísse a etiqueta do INMETRO ou o Selo Procel?". O resultado demonstrou que $84,5 \%$ dos participantes afirmaram que não especificariam sistemas e aparelhos não certificados, contra $15,5 \%$ que responderam positivamente a indagação.

\section{Gráfico 4 - Conhece a ENCE do INMETRO?}

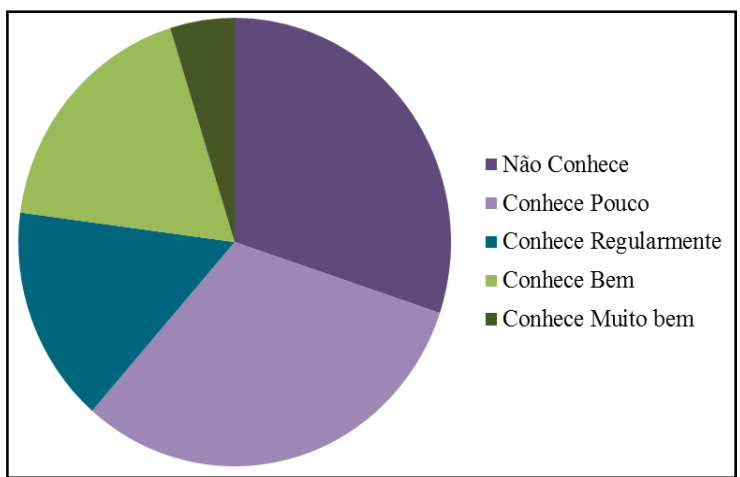

Fonte: Elaboração própria

\section{Gráfico 5 - Conhece a Etiqueta PBE Edifica?}

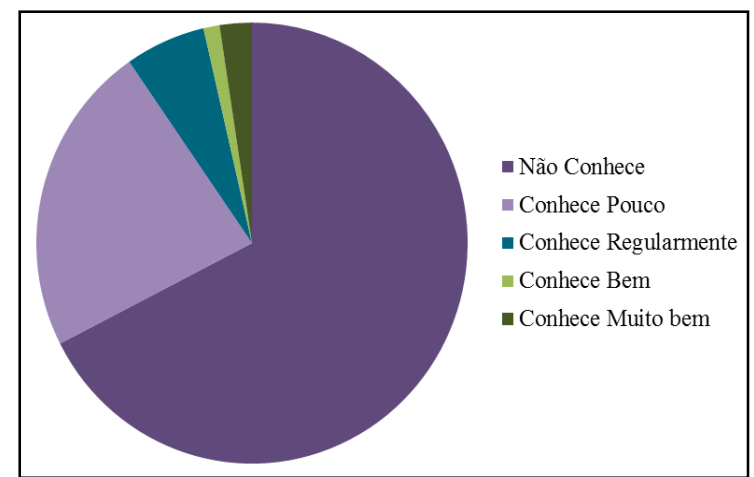

Fonte: Elaboração própria

Como esperado, a quantidade de pessoas que conhecem a Etiqueta PBE Edifica foi menor que a dos que conhecem a ENCE. Parte expressiva dos arquitetos $(67,5 \%)$ respondeu que não conhecem a Etiqueta PBE Edifica, 22,9\% conhecem pouco, 6\% conhecem regularmente, 2,4\% conhecem muito bem e 1,2 conhecem bem (Gráfico 5). Quando questionados sobre o interesse em conhecer ou aprofundar o conhecimento sobre a etiqueta de edificações, 97,6\% dos profissionais estudados neste artigo afirmaram estar interessados em receber informações a respeito dela. Entretanto, a obrigatoriedade da etiquetagem foi encarada com menor entusiasmo, visto que a questão "Você concorda ou discorda com a obrigatoriedade da Etiqueta PBE Edifica?" contou com a concordância por parte de $84,3 \%$ dos respondentes.

\section{CONSIDERAÇÕES FINAIS}

A importância da Etiqueta PBE Edifica e o pouco interesse dos profissionais da construção civil por ela apontaram a necessidade de avaliar a atuação destes relacionada 
à Eficiência Energética em Edificações. A análise dos dados coletados dos arquitetos e urbanistas do estado de Mato Grosso do Sul confirmaram o pouco interesse, por parte desta classe profissional, pela Etiqueta PBE Edifica e a temática da EEE, visto que a pequena quantidade de questionários preenchidos fornece suporte para este entendimento.

Associado ao Censo dos Arquitetos e Urbanistas (CAU/BR, 2012), esta conclusão é reforçada pela afirmação de $73,39 \%$ dos arquitetos de que não existem áreas no mercado não exploradas por eles. Esta postura não só limita a expansão da profissão no campo da etiquetagem de EEE, mas também em outras áreas, alertando para a importância de trabalhar para a transformação do pensamento de grande parcela destes profissionais.

Os dados também permitem o entendimento de que os cursos de graduação realizados pelos participantes da pesquisa apresentam limitações quanto à EEE, pois $41 \%$ dos arquitetos não tiveram disciplina com enfoque em EEE nesta fase de suas formações e apenas $8,5 \%$ deles afirmaram que os conhecimentos adquiridos na graduação sobre o tema são suficientes para a atuação em suas profissões.

A comparação entre a utilização dos conceitos de EEE real e a utilização que os respondentes julgam realizar mostrou que a maioria $(69,9 \%)$ 'raramente' atua de acordo com os critérios da Etiqueta PBE Edifica, apesar de a maior parte (67\%) acreditar atuar segundo os conceitos de EEE 'regularmente' ou 'quase sempre'.

Quando questionados sobre a Etiqueta PBE Edifica, 67,5\% dos arquitetos disseram que não a conhecem, entretanto $97,6 \%$ têm interesse em receber informações sobre ela. Mesmo que este dado pareça contrário à conclusão de que os arquitetos e urbanistas demonstraram pouco interesse pela pesquisa, importa esclarecer que foi necessário trabalhar com uma amostra de oportunidade, logo, os que participaram da pesquisa tendem a ser a parcela da população estudada que apresenta maior interesse ou conhecimento sobre o tema.

Como este artigo apresenta parte dos resultados de um trabalho de mestrado, ainda será possível aprofundar as informações cruzando os dados descritos neste trabalho com informações sobre formação e vida profissional, também coletadas através do questionário formulado. Ainda serão somadas à análise as demais categorias profissionais omitidas neste estudo, a fim de diagnosticar as principais limitações e desenvolver estratégias para mitigar os problemas encontrados.

\section{AGRADECIMENTOS}

Os autores agradecem à Eletrobras, ao CNPq e a CAPES, pelo apoio financeiro recebido.

\section{REFERÊNCIAS}

BELL, Judith. Projeto de Pesquisa: Guia para pesquisadores iniciantes em educação, saúde e ciências sociais. Porto Alegre: Artmed, 2008. $4^{\mathrm{a}}$ Edição.

BRASIL. Subchefia para Assuntos Jurídicos. Lei n. ${ }^{\circ} \mathbf{1 0 . 2 9 5}$, de 17 de outubro de 2001. Disponível em: < http://www.planalto.gov.br/ccivil_03/Leis/LEIS_2001/L10295.htm>. Acesso em: 24 jan. 2012.

CONSELHO DE ARQUITETURA E URBANISMO DO BRASIL (CAU/BR). Censo Arquitetos e Urbanistas: CAU/MS. Brasília: CAU/BR, 2012. Disponível em: 〈〉. Acesso em: 12 fev. 2014. 
FOSSATI, Michele; LAMBERTS, Roberto. Eficiência Energética da Envoltória de Edifícios de Escritórios de Florianópolis: Discussões sobre a aplicação do método prescritivo do RTQC. Ambiente Construído, Porto Alegre v.10, n.2 p.59-69, abr.jun. 2010.

GIL, Antonio Carlos. Métodos e Técnicas de Pesquisa Social. São Paulo: Atlas, 2011. 6 a Edição.

GÜNTHER, Hartmut (2003). Como Elaborar em Questionário. Série: Planejamento de Pesquisa nas Ciências Sociais, n. 1. Brasília: UnB, Laboratório de Psicologia Ambiental. Disponível em <www.psi-ambiental.net/pdf/01Questionario.pdf. Acesso em: 20 de jun de 2012.

INMETRO. Instituto Nacional de Metrologia, Normalização e Qualidade Industrial. Tabelas de produtos etiquetados. Disponível em: < http://www.inmetro.gov.br/consumidor/tabelas.asp>. Acesso em: 30 de julho de 2014.

. Instituto Nacional de Metrologia, Normalização e Qualidade Industrial. Portaria ${ }^{\circ} 50$, de 1 de fevereiro de 2013. Regulamento de Avaliação da Conformidade do Nível de Eficiência Energética (RAC). Brasília, 2013. Disponível em: <http://cb3e.ufsc.br/sites/default/files/projetos/etiquetagem/RTAC001961.pdf >. Acesso em: 28 de abril de 2013.

. Instituto Nacional de Metrologia, Normalização e Qualidade Industrial. Portaria ${ }^{\circ} 18$, de 16 de janeiro de 2012. Regulamento Técnico da Qualidade do Nível de Eficiência Energética de Edifícios Residenciais (RTQ-R). Brasília, 2012. Disponível em: $<$ http://cb3e.ufsc.br/sites/default/files/projetos/etiquetagem/residencial/downloads/RTAC001788.p df >. Acesso em: 28 de abril de 2013.

Instituto Nacional de Metrologia, Normalização e Qualidade Industrial. Portaria $n^{\circ} 372$, de 17 de setembro de 2010. Regulamento Técnico da Qualidade do Nível de Eficiência Energética de Edifícios Comerciais, de Serviço e Públicos (RTQ-C). Brasília, 2010. Disponível

em:

<http://cb3e.ufsc.br/sites/default/files/projetos/etiquetagem/comercial/downloads/RTQ-

C_372_com_Portaria_Complementar.pdf $>$. Acesso em: 28 de abril de 2013.

KRÜGER, Eduardo Leite; MORI, Fabiano. Análise da Eficiência Energética da Envoltória de um Projeto Padrão de uma Agência Bancária em Diferentes Zonas Bioclimáticas Brasileiras. Ambiente Construído, Porto Alegre v.12, n.3 p.89-106, jul./set. 2012.

MARCONI, Marina de Andrade; LAKATOS, Eva Maria. Técnicas de Pesquisa: planejamento e execução de pesquisas, amostragens e técnicas de pesquisa, elaboração, análise e interpretação de dados. São Paulo: Atlas, 2011. $7^{\mathrm{a}}$ Edição.

MINISTÉRIO DE MINAS E ENERGIA (MME). Secretaria de Planejamento e Desenvolvimento Energético. Departamento de Desenvolvimento Energético. Plano Nacional de Eficiência Energética; Premissas e Diretrizes Básicas (PNEf), 2011. Disponível em: < http://www.mme.gov.br/mme/galerias/arquivos/PlanoNacEfiEnergetica.pdf > Acesso em: $17 \mathrm{de}$ abril de 2013.

MINISTÉRIO DE MINAS E ENERGIA (MME). Comitê Gestor de Indicadores e Níveis de Eficiência Energética. Etiquetagem de Eficiência Energética de Edificações. Brasília, 2009.

PEREIRA, Fernando Oscar Ruttkay et al. Disseminação da Etiquetagem de Eficiência Energética de Edificações Através de um Curso a Distância em Ambiente Virtual de Aprendizagem. In: XIII Encontro Nacional de Tecnologia do Ambiente Construído. Canela-RS, 2010.

SILVA, Arthur Santos; GIONGO, Michele; ANDREASI, Wagner Augusto. Planilha Eletrônica para a Avaliação da Eficiência Energética de Edificações e Memorial de Cálculo de Acordo com o RTQ-C. In: XI Encontro Nacional de Conforto no Ambiente Construído. Búzios-RJ, 2011.

RICHARDSON, Roberto Jarry; colaboradores. Pesquisa Social: Métodos e Técnicas. São Paulo: Atlas, 2009. $3^{\text {a }}$ Edição. 